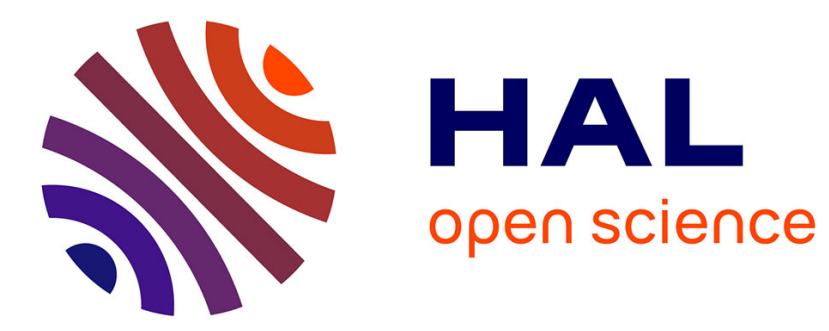

\title{
Novel pendant azobenzene/polymer systems for second harmonic generation and optical data storage
}

\author{
Mitica Spiridon, Konstantinos Iliopoulos, Florica Jerca, Valentin Jerca, \\ Dumitru Vuluga, Dan Vasilescu, Denis Gindre, Bouchta Sahraoui
}

\section{To cite this version:}

Mitica Spiridon, Konstantinos Iliopoulos, Florica Jerca, Valentin Jerca, Dumitru Vuluga, et al.. Novel pendant azobenzene/polymer systems for second harmonic generation and optical data storage. Dyes and Pigments, 2015, 114, pp.24-32. 10.1016/j.dyepig.2014.10.010 . hal-01390939

\section{HAL Id: hal-01390939 \\ https://hal.science/hal-01390939}

Submitted on 7 Sep 2021

HAL is a multi-disciplinary open access archive for the deposit and dissemination of scientific research documents, whether they are published or not. The documents may come from teaching and research institutions in France or abroad, or from public or private research centers.
L'archive ouverte pluridisciplinaire HAL, est destinée au dépôt et à la diffusion de documents scientifiques de niveau recherche, publiés ou non, émanant des établissements d'enseignement et de recherche français ou étrangers, des laboratoires publics ou privés. 


\title{
Novel pendant azobenzene/polymer systems for second harmonic generation and optical data storage
}

\author{
Mitica Cezar Spiridon a, b, Konstantinos Iliopoulos c, d, *, Florica Adriana Jerca a , \\ Valentin Victor Jerca a, b, Dumitru Mircea Vuluga a , Dan Sorin Vasilescu ${ }^{\text {b }}$, Denis Gindre ${ }^{c}$, \\ Bouchta Sahraoui ${ }^{\mathrm{C}, * *}$
}

${ }^{a}$ Centre for Organic Chemistry Costin D. Nenitescu, Romanian Academy, 202B Spl. Independentei CP 35-108, 060023 Bucharest, Romania

b University "POLITEHNICA" of Bucharest Department of Polymer Science, 149 Calea Victoriei, 010072 Bucharest, Romania

' LUNAM Université, Université d'Angers, CNRS UMR 6200, Laboratoire MOLTECH-Anjou, 2 Bd Lavoisier, 49045 Angers Cedex, France

${ }^{\mathrm{d}}$ Institute of Chemical Engineering Sciences, Foundation for Research and Technology Hellas (FORTH/ICE-HT), 26504 Patras, Greece

New poly(methyl methacrylate)s bearing push-pull azo-moieties, with the azo-dye content ranging from $31 \mathrm{wt} \%$ to $100 \mathrm{wt} \%$, are synthesized by (co)polymerization of a methacrylamide-based azomonomer. The high reactivity of the colored monomer allowed well-balanced structures to be achieved, characterized by a suitable thermal stability. The second harmonic generation efficiency of the poled samples is investigated by means of the SHG Maker fringes setup. Features that hinder the translation of the azo-moiety optical nonlinearity in the material at the macroscopic level are debated. The results underline the role of chromophore-chromophore and chromophore-polymer interactions on the alignment of the azo-moieties. The polarity of the polymer matrix is proven to influence the chromophore-chromophore interactions. Two-photon absorption is employed for gray scale encoding of second harmonic signals on poled thin films, thus pointing out the possibility to employ these new materials for optical data storage applications.

\section{Introduction}

Nowadays, there is an increasing research interest in organic materials which exhibit significant nonlinearities, as they can be used in a diversity of photonic applications [1-6]. Considering the development of multimedia and electronic communication networks, there is a tremendous need for data storage. Hence intense research activity is ongoing to find optical data storage materials, as well as suitable processes, for surpassing the capacity limits of the currently utilized storage media [7]. In this direction we have recently demonstrated the possibility to store information in coumarin-based copolymer thin films by using photo-induced dimerization $[8,9]$. Namely, the dimerization of coumarin moieties resulted in a local modification of the Second Harmonic

* Corresponding author. Institute of Chemical Engineering Sciences, Foundation for Research and Technology Hellas (FORTH/ICE-HT), 26504 Patras, Greece. Tel.: +30 2610965209 .

** Corresponding author. Tel.: +33241735489.

E-mail addresses: kostiliopoulos@gmail.com (K. Iliopoulos), bouchta.sahraoui@ univ-angers.fr (B. Sahraoui).
Generation (SHG) efficiency, which was, in turn, used to store the data.

In recent years, azo-polymers continued to attract attention as a consequence of the significant nonlinearities $[10,11]$ of azo dyes and the promising stability, rigidity, and processability of the corresponding polymers [12]. Also, it has been shown that such polymers can be used in a wide range of applications, including optical data storage [6,13-16], due to the reversible trans-cis-trans photoisomerization [17] and the consequent photo-induced effects [18]. In order to meet specific requirements, a wide variety of azobenzene/polymer systems have been investigated for a quantitative understanding of the structure-properties relationship [19]. Therefore, different azo dyes have been tailored by aromatic ring substitution with appropriate electron-donor/-acceptor groups [20], i.e. push-pull azobenzenes. Countless polymer backbones [21-23] have been used as scaffolds for azo-moieties, as to endow certain physical properties. Several approaches [24-26] have been employed to embed suitable azo dyes in polymer matrices. Guesthost systems are usually preferred because various NLO chromophores can be mixed with polymers, and also because it is a simple and cost-effective method. However, only physical bonds are 
established between the two components, so their practical usability is strongly limited by several drawbacks, such as: excessive chromophore aggregation, the decrease of the glass transition temperature, macroscopic phase separation especially at elevated temperatures (i.e. processing temperatures) [10]. The photoactive azobenzenes have been covalently attached to the matrix to overcome the disadvantages of guest-host type systems. An organic synthesis strategy is needed in order to overcome the encountered difficulties, i.e. facile control over the chromophore load, retaining the push-pull character of the azo-moieties, and so forth.

The general requirement for a NLO response in any material is an asymmetric response of the electronic system [27,28]. Thus, push-pull type azobenzenes [10], having a strongly asymmetric electron distribution, are ideal molecules. However, azo-polymers are isotropic, displaying a very low macroscopic second-order NLO response. Higher SHG is achieved only after a noncentrosymmetric polar ordering of the chromophores [29]. In practice, this requirement is attained using various methods, i.e. corona poling [30].

In this framework, we designed a series of new poly(methyl methacrylate)s bearing a push-pull type azo-moieties (Scheme 1), covalently attached from the acceptor site. A simple and efficient organic synthesis approach is employed in order to yield balanced azo-polymer structures. The SHG efficiency of poled azo-polymer thin films is investigated by the SHG Maker Fringes technique. A necessary comparison is carried out between the azobenzene containing poly(methyl methacrylate)s and some poly(styrene)s [31] containing the same type of azo-moieties, that we have recently synthesized by another approach. The overall impact of the polymer matrix type and various chromophore loads is debated. We obtained two dimensional SHG images of the samples by employing SHG microscopy and we show that optical data storage can be successfully achieved in these structures.

\section{Experimental section}

\subsection{Nonlinear optical techniques}

\subsubsection{First-order hyperpolarizability determination using the} solvatochromic method

The nonlinear optical first-order hyperpolarizability $(\beta)$ includes two parts in a donor- $\pi$-acceptor molecule: one is the hyperpolarizability resulting from charge separation induced by the high field $\left(\beta_{\text {add }}\right)$, and the other part is the hyperpolarizability from the contribution of charge transfer state $\left(\beta_{\mathrm{CT}}\right)$. The term $\beta_{\mathrm{CT}}$, usually represents the main part of $\beta$, and can be used to describe the nonlinear optical properties of molecules with an intensive intramolecular electron transfer structure [32]. Here the first-order hyperpolarizabilities of organic chromophores have been measured by the solvatochromic method. This method is based on the two-level quantum-mechanical model where only terms that involve either the ground or the first excited singlet state are considered.

The quantum-mechanical two-level model yields the following expression for $\beta_{\mathrm{CT}}$ :

$\beta_{\mathrm{CT}}=\frac{3}{2 \varepsilon_{0} \hbar^{2}} \frac{\omega_{\mathrm{eg}}^{2}}{\left(\omega_{\mathrm{eg}}^{2}-4 \omega^{2}\right)\left(\omega_{\mathrm{eg}}^{2}-\omega^{2}\right)} \Delta \mu \cdot \mu_{\mathrm{eg}}^{2}$

where $\Delta \mu=\mu_{\mathrm{e}}-\mu_{\mathrm{g}}$ is the difference between the excited and the ground-state dipole moments, $\mu_{\text {eg }}$ is the transition dipole moment between the ground and the excited state, $\omega_{\mathrm{eg}}$ is the transition frequency, while $\omega$ is the laser frequency.

The transition frequency and the transition dipole moment can be ascertained by recording the UV/Vis absorption spectrum of the substance in solution. Whereas $\omega_{\mathrm{eg}}$ is just the frequency of maximum absorption, $\mu_{\mathrm{eg}}$ is related to the overall strength of the transition. According to general quantum mechanics, $\mu_{\text {eg }}$ can be determined from the area under the absorption band, using Equation (2).

$\int \xi \mathrm{d} \omega=\frac{2 \pi^{2} \omega_{\mathrm{eg}} N_{\mathrm{A}}}{3 \ln 10 \varepsilon_{0} c h} \frac{f^{2}}{n} \mu_{\mathrm{eg}}^{2}$

where $N_{\mathrm{A}}$ is Avogadro's number, $\varepsilon_{0}$ is the vacuum permittivity, $c$ is the speed of light, $h$ is the Planck's constant, $\xi$ is the molar extinction coefficient; $f^{2} / n$ is a correction factor accounting for the influence of the dense medium on the absorption process, and, last but not least $n$ is the refractive index of the solvent (see Equation (3)).

$\frac{f^{2}}{n}=\frac{\left(n^{2}+2\right)^{2}}{9 n}$

From the transition dipole moments, the corresponding oscillator strengths $f$ can be calculated according to relation (4) [33].

$f=\frac{2 m \omega_{\mathrm{eg}}}{e^{2} \hbar} \mu_{\mathrm{eg}}^{2}$

where $m$ represents the electron mass and $e$ is the elemental charge.

The ground-state dipole moment can be determined using Debye-Guggenheim equation or by quantum calculation. In our case, we used the last method.

The determination of the excited-state dipole moment remains the most critical part of the experiment. Here the solvatochromic effect in the UV-Vis spectrum can be used. Various theoretical treatments of solvatochromic shift in absorption frequency of a
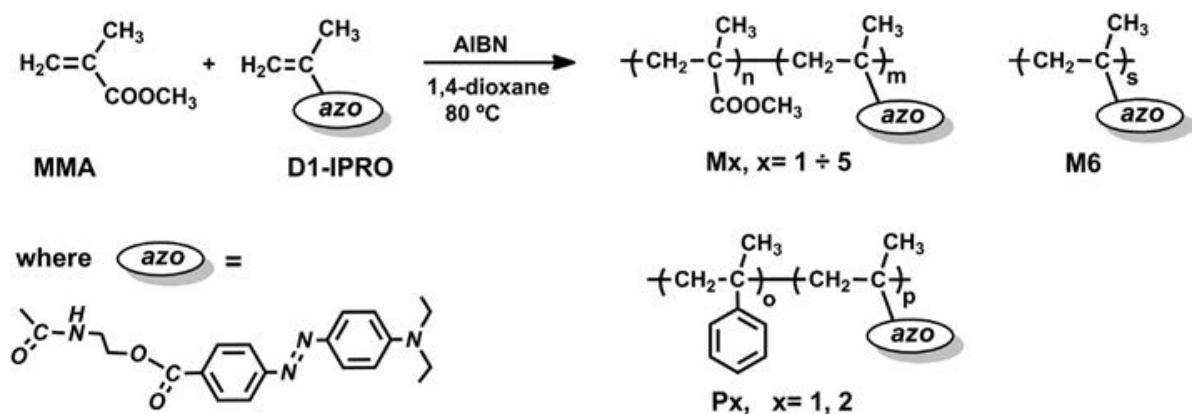

Scheme 1. Synthetic route of Mx azo-polymers and the chemical structure of Px azo-polymers. 
molecule have been developed and one of the useful expressions is that due to McRae [34] and given by Equation (5).

$$
\begin{aligned}
\omega_{\mathrm{eg}}^{\nu}-\omega_{\mathrm{eg}}=-\frac{1}{4 \pi \varepsilon_{0} \hbar a^{3}} \cdot[ & 2\left(\mu_{\mathrm{e}}-\mu_{\mathrm{g}}\right) \mu_{\mathrm{g}} \times\left(\frac{\varepsilon-1}{\varepsilon+2}-\frac{n^{2}-1}{n^{2}+2}\right) \\
& \left.-\left(\mu_{\mathrm{e}}^{2}-\mu_{\mathrm{g}}^{2}\right) \cdot \frac{n^{2}-1}{2 n^{2}+1}\right]
\end{aligned}
$$

where $\omega_{\mathrm{eg}}^{v}$ is the transition frequency in diluted vapor, $\varepsilon$ and $n$ are the dielectric constant and the refractive index of the solvent, and $a$ is the radius of a spherical cavity occupied by the chromophore (Onsager radius). A good estimation of the cavity radius is of great importance [33], therefore a reasonable approximation for $a$, is given by Equation (6).

$a=r_{\mathrm{u}}+0.5 r_{\mathrm{v}}$ when $1 / 2 r_{\mathrm{u}}<r_{\mathrm{v}}<2 r_{\mathrm{u}}$

where $r_{\mathrm{u}}$ and $r_{\mathrm{v}}$ are the spherical radii of the solute $u$ and the solvent $v$ molecules, respectively. Because the density of the solute is difficult to be measured, the values of $r_{\mathrm{u}}$ and $r_{\mathrm{v}}$ can be quantified by relations (7) and (8).

$r_{\mathrm{u}}=\left(\frac{3 V_{\mathrm{u}}}{4 \pi}\right)^{1 / 3}$

$r_{\mathrm{v}}=\left(\frac{3 M_{\mathrm{V}}}{4 \pi N_{\mathrm{A}} \rho_{\mathrm{v}}}\right)^{1 / 3}$

where $M_{\mathrm{v}}$ and $\rho_{\mathrm{v}}$ are the molecular weight and density of the solvent, while $V_{\mathrm{u}}$ is the volume that can be estimated according to Immirzi's theory. [35]

For the solvatochromic measurements, we have chosen solvents where little or no specific type of interaction (either internally or with solute other than electrostatic dipole-dipole forces) was to be expected. The solvents we have used were: chlorobenzene, toluene, anisole, ethyl acetate, tetrahydrofuran, acetone, $N, N^{\prime}$-dimethylformamide and dimethyl-sulfoxide. The data for Equation (5) were fitted by means of linear regression so that to yield the $\mu_{\mathrm{e}}$ values.

\subsubsection{Second harmonic generation Maker Fringes setup}

The SHG efficiency of the samples has been investigated by means of the SHG Maker Fringes setup in transmission configuration. A Nd: $\mathrm{YVO}_{4}$ laser with a repetition rate $10 \mathrm{~Hz}$ delivering $30 \mathrm{ps}$ pulses at $1064 \mathrm{~nm}$ has been employed for the measurements. The polarization and the power of the incident laser beam on the sample have been precisely adjusted by means of a $\lambda / 2$ waveplate and a polarizer. The incident laser energy has been measured with a calibrated energy-meter. Subsequently, the laser beam has been focused by a $250 \mathrm{~mm}$ lens on the sample, while the latter has been positioned in a rotational stage. The rotational stage allowed the variation of the incident angle around the normal of the incident beam. A KG3 filter has been used in order to cut off the fundamental laser beam at $1064 \mathrm{~nm}$, while an interference filter (at $532 \mathrm{~nm}$ ) has been employed to preserve only the SHG beam. The SHG beam has been detected by means of an appropriate photomultiplier (after being attenuated with sufficient neutral density filters), then smoothed by a boxcar average. The averaged values of the SHG have been stored as a function of the incident angle by means of a homemade Labview program, which was also controlling the position of the rotation stage.

The obtained data have been examined using the model of Herman-Hayden [36] in order to find the effective values of the second order nonlinear susceptibility $\left(\chi_{\text {eff }}^{(2)}\right)$. The advantage of this model is that it takes into account the linear absorption of the material under investigation. The second harmonic generation intensity is given by the following equation:

$$
\begin{aligned}
I_{2 \omega}^{s-p}(\theta)= & \frac{128 \pi^{5}}{c \lambda^{2}} \frac{\left[t_{\mathrm{af}}^{1 s}\right]^{4}\left[t_{\mathrm{fs}}^{2 p}\right]^{2}\left[t_{\mathrm{sa}}^{2 p}\right]^{2}}{n_{2 \omega}^{2} \cos ^{2} \theta_{2 \omega}} I_{\omega}^{2}\left(L \chi_{\mathrm{eff}}^{(2)}\right)^{2} \\
& \times \exp \left[-2\left(\delta_{1}+\delta_{2}\right)\right] \frac{\sin ^{2} \Phi+\sinh ^{2} \Psi}{\Phi^{2}+\Psi^{2}}
\end{aligned}
$$

where $I_{2 \omega}$ and $I_{\omega}$ are is the SHG and fundamental intensities, $\lambda$ is the laser excitation wavelength, $t_{\mathrm{af}}^{1 s}, t_{\mathrm{fs}}^{2 p}, t_{\mathrm{sa}}^{2 p}$ are the transmission coefficients for the air/film, film/substrate and substrate/air interfaces $L$ is the thickness of the investigated film. The phase angles $\Phi$ and $\Psi$ are given by the following equations:

$$
\begin{aligned}
& \Phi=\frac{2 \pi L}{\lambda}\left(n_{\omega} \cos \theta_{\omega}-n_{2 \omega} \cos \theta_{2 \omega}\right) \\
& \Psi=\delta_{1}-\delta_{2}=\frac{2 \pi L}{\lambda}\left(\frac{n_{\omega} \kappa_{\omega}}{\cos \theta_{\omega}}-\frac{n_{2 \omega} \kappa_{2 \omega}}{\cos \theta_{2 \omega}}\right)
\end{aligned}
$$

where $\theta_{\omega}, \theta_{2 \omega}$ are such that $\sin \theta_{\omega}=\sin \theta / n_{\omega}$ and $\sin \theta_{2 \omega}=\sin \theta / n_{2 \omega}$, $\mathrm{n}_{\omega}, \mathrm{n}_{2 \omega}$ are the refractive indexes at the fundamental and SHG wavelengths and $\kappa_{\omega}, \kappa_{2} \omega$ are the corresponding extinction coefficients of the samples at the frequencies $\omega$ and $2 \omega$ respectively.

\subsubsection{SHG microscopy technique setup}

Two-dimensional SHG images over the investigated samples have been obtained by means of a SHG microscopy setup. The same setup has been utilized in order to perform optical data storage in the thin azobenzene containing polymer films. A Ti:Sapphire laser (Tsunami, Spectra Physics) has been employed, which is tunable in the range 700-1080 $\mathrm{nm}$ and can provide 120 fs laser pulses with a repetition rate of $80 \mathrm{MHz}$. The laser beam has been focused by an objective lens $(\times 20$ or $\times 50$ magnification $)$ of an inverted modified microscope (IX 71, Olympus), while the laser power could be adjusted by an electro optic modulator. The angular deviation of the laser beam has been achieved by means of two galvanometric mirrors allowing a rapid scanning of the SHG efficiency over the material. A home-made Labview program provided the possibility to precisely adjust the polarization and the intensity of the laser beam and to control the amplitude of the galvanometric mirrors, which is related with the size of the scanned area. With the same program the number of pixels of each 2-D SHG image, the exposure time for each pixel and the position of the thin film have been controlled. The latter has been achieved by placing the thin films on $\mathrm{XYZ}$ motorized stages (Newport) controlled by an 8 axes Motion Controller/Driver (XPS, Newport). The SHG signal has been detected by means of a photon counter after blocking the residual incident laser beam by a short-pass filter (BG39, Schott). The SHG signal has been stored for each position of the laser beam with respect to the sample, providing the 2-D images. The size of the laser beam on the sample was about $1 \mu \mathrm{m}$ which offered the possibility to obtain high resolution SHG images. A second optical path installed in the same inverted microscope consisting of a collimated LED light source and a CCD camera allows recording of optical images of the same zones investigated during the nonlinear optical studies.

\subsection{Instrumentation}

FT-IR spectra were recorded on a Bruker Vertex 70 spectrometer fitted with a Harrick MVP2 diamond ATR device. ${ }^{1} \mathrm{H}$ NMR spectra were taken in $\mathrm{CDCl}_{3}$ on a Varian Unity Spectrometer at $400 \mathrm{MHz}$ at $30{ }^{\circ} \mathrm{C}$. The UV-Vis spectra were recorded on an Ocean Optics High- 
Resolution Fibber Optic Spectrometer HR 4000. The thermal analysis and glass transition temperatures $\left(T_{\mathrm{g}}\right.$ ) (simultaneous TGA-DSC, MS hyphenated) was performed on a NETZSCH STA 449C Jupiter system, coupled to an Aëolos II MS detector. Degradations were performed in the scanning mode for all samples, from ambient temperature up to $750{ }^{\circ} \mathrm{C}$, at a heating rate of $10{ }^{\circ} \mathrm{C} / \mathrm{min}$ under helium flow ( $25 \mathrm{~mL} / \mathrm{min})$. The number average molecular weights (Mn) have been evaluated by SEC with Wyatt Heleos II Multi Angle Light Scattering in-line and batch detector; using $N, N^{\prime}$-dimethylformamide with $50 \mathrm{mmol}$ of $\mathrm{LiCl}$ as eluent (flow rate $1 \mathrm{~mL} / \mathrm{min}$ ), at $35{ }^{\circ} \mathrm{C}$.

\subsection{Synthesis and poled thin films preparation}

\subsubsection{Materials}

Methyl methacrylate (MMA, Merck) was purified by low pressure distillation. 2,2'-Azo-bis(2-methylpropionitrile) (AIBN, Aldrich) was recrystallized from ethanol prior to use. Dry 1,4dioxane resulted after distillation over sodium. All other reagents and solvents were commercially available and have been used as such.

\subsubsection{Poly(2-methacrylamidoethyl 4-((4-(diethylamino)phenyl) diazenyl)benzoate-co-styrene) (Px)}

The azo-polymer synthesis was recently described by us elsewhere [31].

\subsubsection{2-Methacrylamidoethyl 4-((4-(diethylamino)phenyl) diazenyl) benzoate (D1-IPRO)}

We have prepared the new azo-monomer according to the reported protocol in Ref. [37]. The material had identical spectroscopic and physical properties to the originally reported material [37].

\subsubsection{Poly(2-methacrylamidoethyl 4-((4-(diethylamino)phenyl)} diazenyl)benzoate) (M6) and poly(2-methacrylamidoethyl 4-((4(diethylamino)phenyl)diazenyl)benzoate-co-methyl methacrylate) (Mx)

These new azo-polymers have been synthesized by free-radical copolymerization. The azo-monomer D1-IPRO was copolymerized with MMA (Scheme 1) using different feed ratios between the comonomers (see Table 1 ).

A representative copolymerization procedure was as follows for copolymer M3: MMA (0.024 mL, $0.23 \mathrm{mmol})$, D1-IPRO (0.092 g, $0.23 \mathrm{mmol})$ and dioxane $(0.4 \mathrm{~mL})$ were mixed in a vial. The resulting mixture was well degassed then AIBN ( $1.5 \mathrm{mg}$ ) was added to prepare the final solution and sealed off under an argon atmosphere. The polymerizations were carried out at $80{ }^{\circ} \mathrm{C}$ for $20 \mathrm{~h}$. After cooling at room temperature, the final reaction mixture

Table 1

Physical data for Mx azo-polymers.

\begin{tabular}{llllllll}
\hline $\begin{array}{l}\text { Polymer } \\
\text { code }\end{array}$ & $x_{\text {D1-IPRo }}{ }^{\mathrm{a}}$ & $X_{\text {D1-IPRo }}{ }^{\mathrm{b}}$ & wt\% ${ }_{\text {D1-IPRO }}{ }^{\mathrm{c}}$ & $T_{\mathrm{g}}\left({ }^{\circ} \mathrm{C}\right)$ & $T_{\mathrm{d}}{ }^{\mathrm{d}}\left({ }^{\circ} \mathrm{C}\right)$ & $\mathrm{Mn}(\mathrm{Da})$ & PDI \\
\hline M1 & 0.15 & 0.1 & 31 & 128.2 & 275 & 20,540 & 1.34 \\
M2 & 0.3 & 0.23 & 55 & 135 & 268 & 31,360 & 1.46 \\
M3 & 0.5 & 0.42 & 75 & 136.2 & 263 & 37,250 & 1.68 \\
M4 & 0.65 & 0.62 & 87 & 134.3 & 259 & 58,440 & 2.25 \\
M5 & 0.8 & 0.79 & 94 & 130.9 & 258 & 62,040 & 2.34 \\
M6 & 1 & 1 & 100 & 126.9 & 248 & 98,040 & 3.45 \\
\hline a Feed molar fractions for D1-IPRO. \\
b Molar fraction for D1-IPRO in copolymers given by ${ }^{1} \mathrm{H}$ NMR spectroscopy. \\
c Weight percentage of the azo-moieties in the polymer matrix. \\
d Temperature represents 1\% weight loss in TGA measurements at heating rate of \\
10 ${ }^{\circ}$ C/min.
\end{tabular}

solution was diluted with chloroform and precipitated in diethyl ether. The copolymer was purified from unreacted monomers by re-precipitation from chloroform in diethyl ether. Subsequently, the products were dried under vacuum at $80{ }^{\circ} \mathrm{C}$ for $24 \mathrm{~h}$. The homopolymer of D1-IPRO (M6) was obtained under the same conditions. All polymers have been obtained with good purities and with the following yields: M1 46\%; M2 51\%; M3 47\%; M4 49\%; M5 54\%; M6 $56 \%$.

${ }^{1} \mathrm{H} \mathrm{NMR}\left(\mathrm{CDCl}_{3}, 30^{\circ} \mathrm{C}\right) \delta(\mathrm{ppm})$ for M3: $8.08(2 \mathrm{H}, \mathrm{o}-\mathrm{ArH}$ to $\mathrm{COOR})$, $7.82(4 \mathrm{H}, \mathrm{m}-\mathrm{ArH}$ to COOR and m-ArH to NEt2), $6.66(2 \mathrm{H}, \mathrm{o}-\mathrm{ArH}$ to $\mathrm{NEt} 2), 4.36$ (2H vicinal to ester group), $3.53\left(3 \mathrm{H},-\mathrm{COOCH}_{3}\right), 3.42$ (2H vicinal to amide group overlap with $\mathrm{CH}_{2}$ from $\mathrm{N}, \mathrm{N}$-diethyl), 1.5-2 (2H from backbone), 0.75-1.5 (3H from backbone overlap with $\mathrm{CH}_{3}$ from $N, N$-diethyl). FT-IR for M3 (ATR): $\nu=1717$ (vs, $\nu(\mathrm{C}=$ O)), 1266 (vs, $\nu(\mathrm{C}-\mathrm{O}-\mathrm{C})$ ), 1131 (vs, $\nu(\mathrm{C}-\mathrm{O})), 1515$ (s, $\nu(\mathrm{C}-\mathrm{N})), 1662$ (s, $\nu(C=0)), 1596$ and 700 (aromatic vibrations) $\mathrm{cm}^{-1}$.

\subsubsection{Thin film preparation}

Thin films of all azo-polymers were obtained onto clear optical glass (fused silica) slides by spin coating. $2.6 \mathrm{wt} \%$ polymer solutions in chloroform were filtered through a $0.2 \mu \mathrm{m}$ pore size PTFE membrane syringe filter, and spin coated using an angular speed of $1000 \mathrm{rpm}$ for $45 \mathrm{~s}$, at $400 \mathrm{rpm} / \mathrm{s}$. Subsequently, the polymer films were annealed in an oven at $60^{\circ} \mathrm{C}$ for one hour, in order to remove any traces of the solvent. The thickness of all films has been measured by means of a $6 \mathrm{M}$ DEKTAK profilometer. In all cases the thickness has been found to be around $2.2 \mu \mathrm{m}$.

\subsubsection{Corona poling}

The azo-polymers have been oriented in a noncentrosymmetric fashion using a corona poling setup [30]. The investigated thin films have been heated close to their glass transition temperature $\left(T_{\mathrm{g}}\right)$ for $10 \mathrm{~min}$, and a strong electric field has been applied by means of two tungsten wires positioned over the film ( $4.5 \mathrm{kV}$ applied) in order to achieve homogeneous alignment of the molecules. Then the sample has been cooled down to room temperature, while the electric field was still applied. The temperature during this experimental procedure has been precisely controlled by means of home-made software.

\section{Results and discussion}

The present study aims to clarify some of the most important issues encountered in designing and developing efficiently sidechain azobenzene containing polymers for second-order NLO applications (i.e. optical information processing), as follows. (i) The synthesis approach must be easily employed, it must ensure the retention of the azo dye nonlinearity after its chemical attachment and it must yield polymer structures with certain physical properties, i.e. thermal stability, film-forming properties. (ii) Properties of the materials that hinder the translation of microscopic (push-pull azo dye) optical nonlinearity to the macroscopic (azopolymer) optical nonlinearity.

Therefore, the co-polymerization reaction of a new reactive azomonomer is presented comparatively with another synthesis method (a polymer analogous reaction) that yields similar polymer structures, highlighting for each approach advantages and disadvantages, respectively. The impact on the NLO response that dictates the trade-off in choosing a poly(methyl methacrylate) or a poly(styrene) matrix, different molecular weights of these matrices, the sequence distribution in copolymers and various chromophore loads is debated in comparison with other reported studies. Additionally, we obtained two dimensional SHG images of the samples by employing SHG microscopy and we show that optical data storage can be successfully achieved in these structures. 


\subsection{FT-IR/ ${ }^{1} H$ NMR characterization}

FT-IR and ${ }^{1} \mathrm{H}$ NMR spectroscopy confirmed the chemical structure of the synthesized copolymers. A typical example is given for M3 copolymer. In the FT-IR spectrum of M3 (see Fig. 1) we can distinguish the characteristic absorptions of the ester bands at 1717 $\left(\nu_{\mathrm{C}}=\mathrm{O}\right), 1266\left(\nu_{\mathrm{C}-\mathrm{O}-\mathrm{C}}\right)$ and $1131\left(\nu_{\mathrm{C}-\mathrm{O}}\right)$; the amide I band at 1662 $\left(\nu_{\mathrm{C}}=0\right)$ and the amide II band at $1515\left(\nu_{\mathrm{C}-\mathrm{N}}\right)$; the substituted benzene rings vibrations from the azo-moieties found at 1596 and 700 , all in $\mathrm{cm}^{-1}$. These spectral features are characteristic for all $\mathrm{Mx}$ copolymers.

The ${ }^{1} \mathrm{H}$ NMR spectrum of M3, as presented in Fig. 2, is a typical example that highlights the azo-polymer formation. The signals for the azo moieties are found at around 8.08, 7.82, and $6.66 \mathrm{ppm}$ (aromatic protons). The signal from $-\mathrm{CH}_{2}-$ of $\mathrm{N}, \mathrm{N}$-diethyl groups overlaps with the signal given by the $-\mathrm{CH}_{2}-$ vicinal to the amide groups and the signal corresponding to the protons of $-\mathrm{O}-\mathrm{CH}_{3}$ from the MMA units, all of these signals are found in the vicinity of $3.5 \mathrm{ppm}$. The signal from $-\mathrm{CH}_{2}-$ vicinal to the ester groups appears at $4.36 \mathrm{ppm}$.

The chemical composition of the azo-polymers were calculated from each spectra based on the integrated peak areas of the aromatic signals from the azo-moieties relative to those given by the protons of $-\mathrm{O}-\mathrm{CH}_{3}$ from the MMA unit. The values are summarized in Table 1. According to these values, the azo-dye content of the copolymers was found to be less than that in the initial feed.

\subsection{Molecular weights of the azo-polymers}

High number average molecular weights (Mn) were attained by copolymerization and the values are given in Table 1 for all polymers together with their polydispersity indices (PDI). The polydispersity index of the polymers ranges between 1.34 and 3.45. The theoretical values of PDI for polymers produced via radical recombination and disproportionation are 1.5 and 2.0, respectively [38]. This suggests a tendency for chain termination by disproportionation at high D1-IPRO feed ratios and probably some chain transfer reactions (see PDI of M6). At low D1-IPRO feed ratios chain termination occurs by combination.

\subsection{Copolymer composition and monomer reactivity ratios}

The microstructure of a polymeric material plays an important role in the behavior of the material toward a variety of external

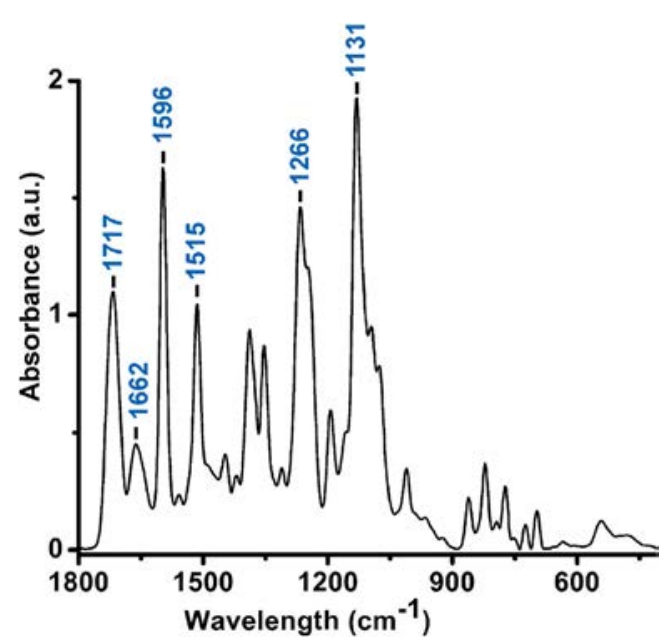

Fig. 1. Typical FT-IR spectrum given for copolymer M3.

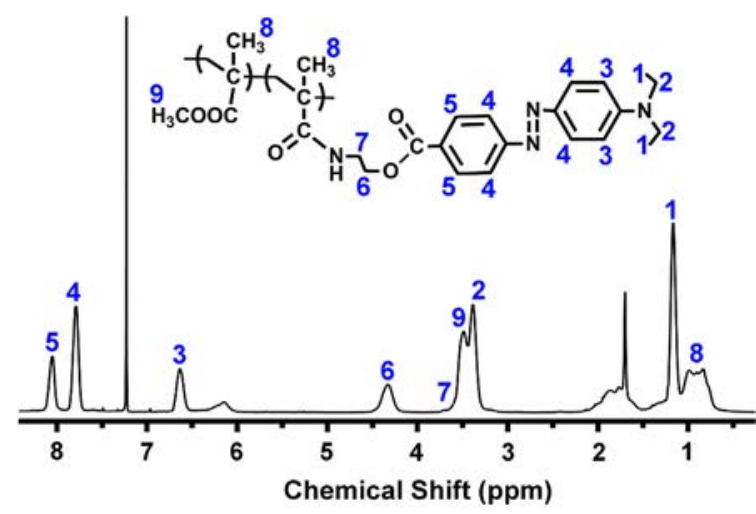

Fig. 2. Typical ${ }^{1} \mathrm{H}$ NMR spectrum in $\mathrm{CDCl}_{3}$ given for copolymer $\mathrm{M} 3$.

stimuli (light, pH) systems, and could be especially important in copolymerizations with monomers of different reactivities. Monomer reactivity ratios provide a tool for estimating the average compositions of copolymers and the relative placement of reactive or functional monomers along the polymer chain.

In order to determine the reactivity ratios, we have used an integral method and the corresponding software, the OptPex2 program [39] provided by Hagiopol and coworkers. Taking into account the obtained values, $r_{\mathrm{MMA}}=1.95$ and $r_{\mathrm{D} 1-\mathrm{IPRO}}=0.94$, it can be said that D1-IPRO favors cross-propagation as opposed to homopropagation and MMA favors homopropagation over crosspropagation. The product of $r_{\mathrm{MMA}}$ and $r_{\mathrm{D} 1 \text {-IPRO }}$ is higher than the unity (1.82), which indicates less random distribution, with a longer sequence of MMA units. Nevertheless, as compare to other azo-monomers [40], this $N$-monosubstituted methacrylamide azomonomer presents a good reactivity since it undergoes homopolymerization and the copolymers synthesized exhibit high molecular weights.

\subsection{Thermal properties}

The data provided by simultaneous TGA-DSC-MS analysis (see Table 1 ), for the entire new series of azobenzene containing pol$\mathrm{y}$ (methyl methacrylate)s and the corresponding azo homopolymer, provides important information regarding the influence of the chemical composition upon the thermal stability and the glass transition temperature. These data are of interest because thermally stable polymers are required for the targeted application. After corona poling, the decay of azo chromophore orientation may be negligible over the device lifetime by employing azo-polymers with suitable $T_{\mathrm{g}}$ values.

All copolymers prepared display a single $T_{\mathrm{g}}$, indicative of the random distribution of the monomer units in the polymer chain. The $T_{\mathrm{g}}$ values are reported in Table 1 and plotted versus composition in Fig. $S 1$. As a comparison, the $T_{\mathrm{g}}$ values attained by Mx azopolymers are higher than those of similar azobenzene (Disperse Red 1) containing homopolymers and copolymers with MMA [41].

The $T_{\mathrm{g}} \mathrm{s}$ are higher than predicted by linear additivity, values ranging from 116 to $131{ }^{\circ} \mathrm{C}$. This suggests strong interactions between the two comonomers, restricting chain motion and thereby raising $T_{\mathrm{g}}$. To quantitatively assess the degree of interactions between MMA and D1-IPRO segments, we have used the Kwei equation [42] to predict the variation of glass transition temperature.

$T_{\mathrm{g}}=\frac{w_{1} T_{\mathrm{g} 1}+k w_{2} T_{\mathrm{g} 2}}{w_{1}+k w_{2}}+q w_{1} w_{2}$ 
where $w_{1}$ and $w_{2}$ are weight fractions of compositions, $T_{\mathrm{g} 1}$ and $T_{\mathrm{g} 2}$ represent the corresponding glass transition temperatures, $k$ and $q$ are fitting constants. The $k$ parameter represents the unequal contributions of components in a mixture to the final $T_{\mathrm{g}}$, while $q$ is used to model the effects of interactions between components, such as hydrogen bonds.

Fig. S1 shows the best-fit curve based on the Kwei equation, where $k$ is 1 and $q$ is 84 . A positive $q$ value of 84 implies that the inter-association interaction between MMA and D1-IPRO units is stronger than the self-association interaction resulting in free volume decrease. This strong interaction can be regarded as a hydrogen bond formed between oxygen from the carbonyl unit of MMA and the $H$ from the $N H$ belonging to the amide group of D1IPRO.

All Mx azo-polymers exhibit good thermal stability with $T_{\mathrm{d}}$ values between 248 and $275{ }^{\circ} \mathrm{C}$ (see Table 1). As evidenced from Fig. S2, TGA curves have characteristic two-step decomposition regions. The first weight loss region appears around $260-350{ }^{\circ} \mathrm{C}$ probably associated with the cleavage of $\mathrm{C}-\mathrm{N}$ bond with elimination of nitrogen $(m / z=28)$ as revealed from mass spectra. Secondary weight loss occurring around $350-490{ }^{\circ} \mathrm{C}$ may be related to main-chain degradation reactions and breakdown of the polymer backbone. For M1 sample methyl methacrylate mass fragment $(m / z=100)$ could also be detected in the first degradation step due to depolymerization. One may conclude that copolymers with high azo dye content show slightly lower thermal stability.

Lowest decomposition temperature of $248^{\circ} \mathrm{C}$, that exceeds by more than $100{ }^{\circ} \mathrm{C}$ the normal service temperature, and $T_{\mathrm{g}}$ higher than $127^{\circ} \mathrm{C}$ qualify these materials for the targeted applications.

\subsection{Nonlinear optical properties of azo-polymers}

\subsubsection{UV-Vis characterization}

The UV/visible absorption spectra of trans isomer for amorphous thin films of Mx series (see Fig. S3) are characterized by a maximum situated around $290 \mathrm{~nm}$ that can be attributed to the $\pi-\pi^{*}$ transitions of the aromatic rings. The strong absorption band that varies from 427 to $449 \mathrm{~nm}$ as the chromophore load decreases corresponds to a $\pi-\pi^{*}$ first single electron transition. The $n-\pi^{*}$ band is completely buried beneath the intense $\pi-\pi^{*}$ band. Hence, one may say that the photo-addressable moieties retain the initial push-pull character after covalent attachment to the polymer matrix.

\subsubsection{First-order hyperpolarizability}

A complete insight into the NLO properties of a model azocompound (D1-EtOxa [31]) that has the same structure with the azo-moieties after chemical attachment is further presented. These data are of interest since it would reveal the efficiency in the translation of the microscopic optical nonlinearity to the macroscopic optical nonlinearity. We employ a crude technique for the determination of the first-order molecular hyperpolarizability tensor $(\beta)$ using the solvatochromic response of the model compound, and DR1 as standard. The ground state dipole moments of the azo dyes were determined by quantum chemical calculations. All the computations were carried out using GAMESS [43] program and the basic set level used was M11/KTZVP [44]. The experimental values of D1-EtOxa and DR1 are summarized in Table 2, where DR1 data were measured under identical experimental conditions. It can be found that the hyperpolarizability of D1-EtOxa is slightly lower than that of DR1. This fact may be attributed to the weaker electron withdrawing effect of the ester group as compared to nitro group.
Table 2

Solvatochromic data and first-order hyperpolarizabilities of the studied molecules.

\begin{tabular}{lllllll}
\hline Compound & $\begin{array}{l}\lambda_{\max }{ }^{\mathrm{a}} \\
(\mathrm{nm})\end{array}$ & $\begin{array}{l}\mu_{\mathrm{g}} \cdot 10^{-29} \\
(\mathrm{C} \mathrm{m})\end{array}$ & $\begin{array}{l}\mu_{\mathrm{eg}} \cdot 10^{-29} \\
(\mathrm{C} \mathrm{m})\end{array}$ & $\begin{array}{l}\mu_{\mathrm{e}} \cdot 10^{-29} \\
(\mathrm{C} \mathrm{m})\end{array}$ & $\begin{array}{l}\beta \cdot 10^{-30} \\
(\mathrm{esu})\end{array}$ & $a^{\mathrm{a}}(\mathrm{nm})$ \\
\hline D1-EtOxa & 461 & 3.07 & 2.24 & 10.6 & 407 & 0.64 \\
DR1 & 499 & 2.87 & 2.19 & 7.54 & 625 & 0.58 \\
\hline
\end{tabular}

a Measured in $N, N^{\prime}$-dimethylformamide.

\subsubsection{Nonlinear optical measurements}

The SHG efficiency of the samples has been investigated by means of the SHG Maker fringes technique, briefly described in Paragraph 2.1.2. The setup has been calibrated before the measurements by using a $0.5 \mathrm{~mm}$ thick Y-cut quartz slab with $\chi^{(2)}=8.07 \times 10^{-12}$ esu $(1 \mathrm{pm} / \mathrm{V})$ and coherence length $20.5 \mu \mathrm{m}$. Measurements have been obtained by recording the SHG efficiency as a function of the incidence angle providing the so-called Maker fringes patterns. The SHG efficiency has been measured before and after aligning the azo chromophores by corona poling, described in the experimental section. Before the corona poling procedure, the samples have been found to exhibit negligible SHG response, which has been expected, taking into account the random chromophore orientation inside the film. However, after the corona poling procedure, the centro-symmetrical character of the films has been "broken" due to the alignment of the dipole moments of the molecules, which leads to a significant SHG response. In order to have direct comparison between the responses of different azopolymers, they all have been studied under the same experimental conditions. In Figs. 3 and 4 characteristic curves of all studied systems are presented.

The second order nonlinear susceptibilities have been determined for the investigated systems by fitting the experimental data according to the Herman-Hayden model, described in the experimental section, and the results are shown in Table 3. A comparison between copolymer P1 and P2 (having 38 wt\% and 64 wt\% azomoieties, respectively) shows an enhancement by about a factor of 2 in the case of P2. On the contrary, the SHG efficiency of copolymer M1 is higher (about a factor of 1.7) as compared with that of copolymer M3. The fact that M1 has $31 \mathrm{wt} \%$ azobenzene and M3 has $75 \mathrm{wt} \%$ seems to be contradictory to the relative SHG efficiencies, as theoretically the SHG intensity is linearly dependent upon the number densities. This divergence from the theoretically expected behaviour, concerning the samples M1 and M3, is probably the consequence of chromophore aggregation that play a

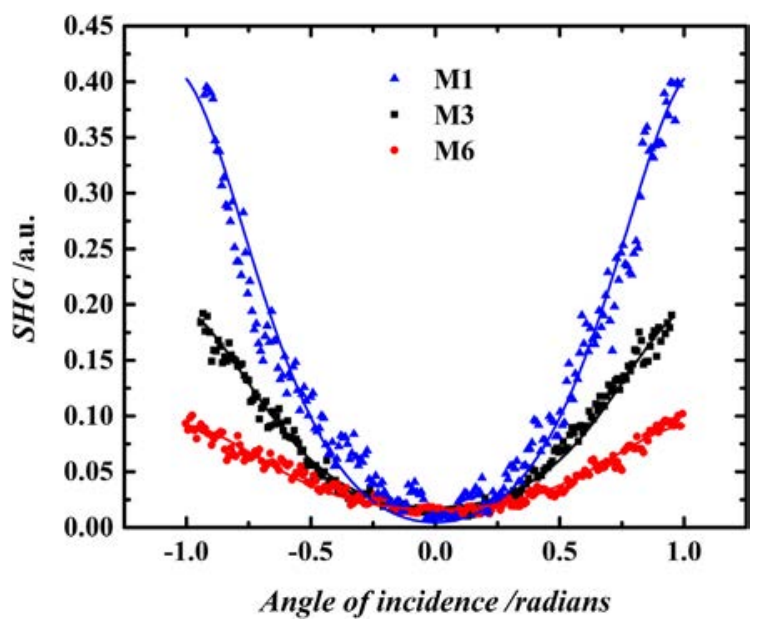

Fig. 3. Characteristic Maker Fringes curves for the systems M1, M3, M6. 


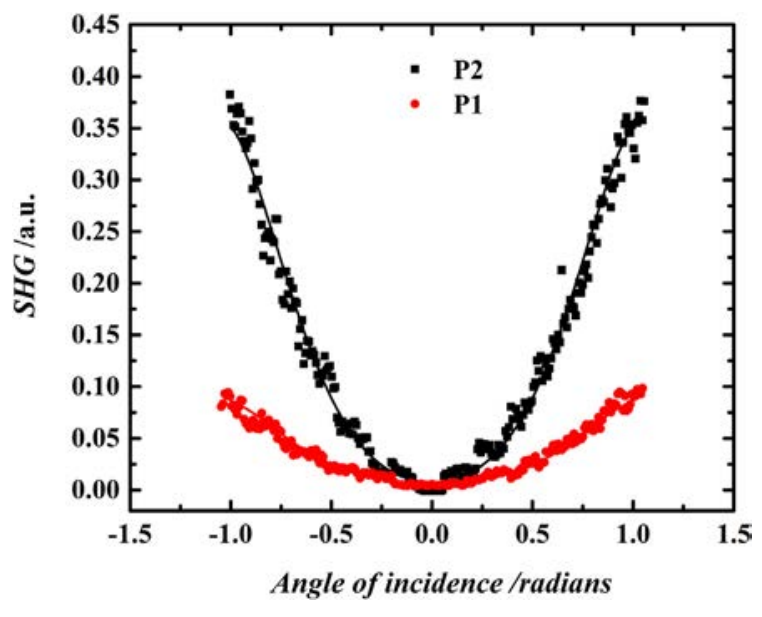

Fig. 4. Characteristic Maker Fringes curves for the systems P2, P1.

dominant role in limiting the translation of molecular to macroscopic optical nonlinearity, confirming earlier studies upon similar systems [45].

Aggregates in azo-polymers are presumably to arise in different forms, i.e. various types of dimers and larger aggregates with different packing geometries. UV-Vis spectroscopy approximately qualitatively estimates the distinct spectral signatures given by aggregate formation. H-aggregates are already encountered in polymers that embed push-pull type azobenzenes [46]. These emerge from aggregation in a parallel way (plane-to-plane stacking) of strong dipolar azo chromophores, which is thermodynamically more favored than a head-to-tail arrangement (end-to-end stacking, J-type).

In the UV-Vis spectra of Mx copolymer series, it can be noticed a systematic blue shift of the absorption maxima as well as a slight broadening of the band as the chromophore concentration increases (see Fig. S3). The change of $\lambda_{\max }$, between the homopolymer M6 film containing 100 wt\% azo-moieties and copolymer M1 containing only $31 \mathrm{wt} \%$ azo-moieties, is about $22 \mathrm{~nm}$. Examination of the UV-Vis spectra for the Px series revealed a similar blue shift, but it is slightly less pronounced (approx. $14 \mathrm{~nm}$, between homo-polymer P6 with 98 wt\% azo-moieties and copolymer P1 with 38 wt\% azo-moieties). Hence, the blue shift in the absorption maximum proves that the aggregates should be of $\mathrm{H}$ type. An additional confirmation for $\mathrm{H}$-aggregate formation is given after subjecting the M6 film to a thermal treatment. By keeping the film for $30 \mathrm{~min}$ at $100{ }^{\circ} \mathrm{C}$, followed by a slow cooling back to room temperature (that allows the azo-moieties to form aggregates), a larger blue shift than for the initial untreated M6 film was noted. The smaller blue shift of absorption in Px series can be related to sequence distributions (tacticity) on the azo-moieties mobility and inter-/intra-molecular interactions, taking into account that Px polymers were obtained by a polymer analogous reaction that implies preformed poly (iso-propenyl-oxazoline-co-styrene)s matrices with different tacticity.

Table 3

Second order nonlinear susceptibilities of the investigated systems.

\begin{tabular}{lll}
\hline Sample code & Number density $\left(\times 10^{21}\right.$ molecules $\left./ \mathrm{cm}^{3}\right)$ & $\chi^{(2)}(\mathrm{pm} / \mathrm{V})$ \\
\hline M1 & 0.79 & $3.26 \pm 0.8$ \\
M3 & 1.91 & $1.90 \pm 0.3$ \\
M6 & 2.55 & $1.44 \pm 0.3$ \\
P1 & 0.97 & $1.45 \pm 0.2$ \\
P2 & 1.63 & $2.89 \pm 0.8$ \\
\hline
\end{tabular}

${ }^{\text {a }}$ Calculated according to Ref. [45].
As previously concluded, H-type aggregates are mainly responsible for the extinguish of the macroscopic SHG response, as a result of the competition between the poling field which arranges the azo-moieties into a non-centrosymmetric fashion and this kind of chromophore-chromophore interactions which drive the azomoieties into a centrosymmetric arrangement. The latter effect is more and more noticeable as the chromophore content increases. The difference in SHG efficiency between M1 and P1 is due to the compatibility of the azo-dye with the polymer matrix. Surprisingly, in the case of Mx series the strongest SHG signal is detected for sample M1 which has a 31 wt\% load of chromophore, while for Px the strongest SHG signal is detected for P2 with a $64 \mathrm{wt} \%$ load of chromophore. PMMA is more polar than polystyrene and the azodye has polar groups (like $N H$ ) which are susceptible to form hydrogen bonds with the matrix (see Section 3.4) that would lead to a better stabilization against chromophore aggregation. Consequently, one can expect the reverse behavior, that the PMMA matrix should overpass the aggregation tendency of the chromophore up to a higher chromophore load. The experimental results contradict this theory, and prove at the same time that the chromophore-chromophore interactions are better suppressed in polystyrene matrix. Detailed SHG investigations for PMMA and polystyrene with different chromophore load are now in progress in order to elucidate this behavior and to determine which copolymer composition generates the strongest SHG signal.

\subsection{SHG microscopy/optical data storage}

The SHG microscopy setup, described in Paragraph 2.1.3, has been utilized in order to obtain 2-D images of the second harmonic generation efficiency and to perform optical data storage in the thin azo-polymer films. Firstly, corona poling has been performed in order to align the chromophores and generate the SHG signal. In Fig. $\mathrm{S} 4$ optical images of the sample M1 can be seen before and after the corona poling procedure. It is obvious that, although before the poling the surface of the sample is homogeneous with only few defects appearing, after the poling small spots are appearing all over the surface. The appearance of these spots is attributed to the aggregates that emerge from an effective alignment along the direction of the field poling, and it has been previously discussed by Rau et al. [47] Two-dimensional SHG images have been obtained for all the investigated samples. The sample M1 combined at the same time high SHG efficiency and very good homogeneity over the surface of the film as it can be seen by examining Fig. S5. For this reason, we have chosen this sample to perform optical data storage. The optical data storage has been achieved through successive isomerization cycles induced through two-photon absorption processes [13]. During these studies, the laser excitation wavelength has been adjusted to be $800 \mathrm{~nm}$ and the laser beam has been focused into the sample by means of a $\times 50$ objective lens. In order to demonstrate the possibility to perform optical data storage in these samples we have recorded the image of the filmmaker Georges Méliès (Fig. S6). The size of this image is $125 \times 125$ pixels and prior to the recording it had been converted into a 2D matrix. In this way each grey level value of the image corresponded to a specific laser power, which was ranging between 0 and $100 \mathrm{~mW}$. As a result each pixel has been irradiated with the appropriate laser power according to the corresponding grey level while the irradiation time for every pixel has been fixed at $1 \mathrm{~ms}$. As a result, the recording time for the image presented in Fig. 5a has been about $15 \mathrm{~s}$.

The reading-out has been performed by scanning the SHG efficiency over the surface, detecting in this way the modulation of the SHG over the recorded area. This modulation has been achieved through the disorientation of the azobenzene moieties due to the 

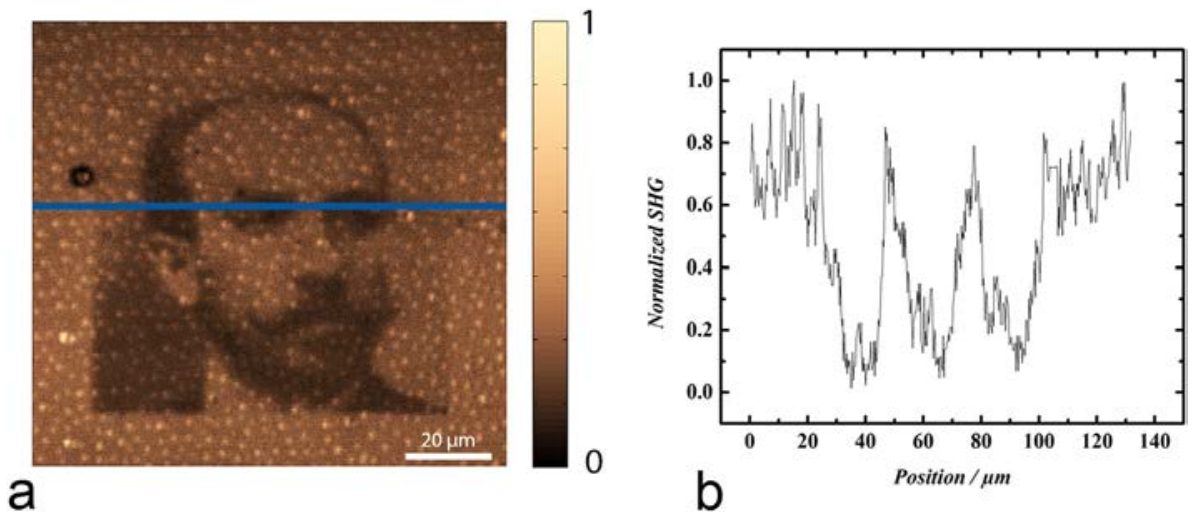

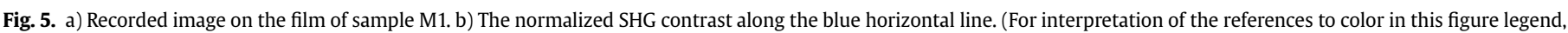
the reader is referred to the web version of this article.)

laser induced trans-cis isomerization. In this sense the nonirradiated areas (laser power $0 \mathrm{~mW}$ ) contain totally aligned chromophores leading to maximum SHG efficiency, while the irradiated areas exhibit a degree of misalignment depending on the laser power used. The image containing the recorded data can be seen in Fig. 5a. Obviously maximum contrast between irradiated and nonirradiated areas has been achieved in the darkest pixels where the incident laser power has been adjusted to be $100 \mathrm{~mW}$ during the recording. In Fig. 5b the normalized SHG contrast along the blue horizontal line shown in Fig. 5a is presented.

\section{Conclusions}

A series of new side-chain poly(methyl methacrylate)s bearing push-pull type azo-moieties was easily synthesized by employing a highly reactive azo-monomer. Their composition was easily controlled through the monomer feed ratio, yielding well-balanced polymer structures with high molecular weights and adequate thermal properties for the targeted application. We also, manage to obtain good optical quality films, a must of their usability in optical information processing.

The covalent attachment approach ensured the retaining of the initial push-pull character of the azo dye in the corresponding azopolymers, as is has been confirmed by UV-Vis. However, for these structures, chromophore aggregation (H-type) played a dominant role in limiting the translation of strong molecular nonlinearity at the macroscopic level, especially when the azo-moiety content increased. Aggregation may be limited by using different polymer matrices.

A peculiar behavior, regarding the compatibility of push-pull azo-moieties and polymer matrices, was revealed when a comparison was carried between the SHG efficiency at various chromophore loads for the new azo-poly(methyl methacrylate)s and similar azo-poly(styrene)s. Surprisingly, the chromophore-chromophore interactions are better suppressed in nonpolar poly(styrene) matrices than in polar poly(methyl methacrylate).

The synthesized azo-polymers prove to be promising enough for encoding optical information. The storage on poled films was performed through controlled disorientation of the azo-moieties by means of successive trans-cis-trans isomerization cycles induced by two-photon absorption. The quadratic dependence on the incident light intensity of both the two-photon absorption and the SHG processes provided a confined recording, thus a high storage capacity. The stored information has been read by scanning the SHG response.

\section{Acknowledgment}

The authors acknowledge the contribution of Konstantinos Iliopoulos, Florica Adriana Jerca, Valentin Victor Jerca and Dumitru Mircea Vuluga being equal to that of the first and reprint author.

K. I. acknowledges the support from the European Commission and the General Secretariat for Research and Technology (Greece) for a National Strategic Reference Framework (NSRF) Project (PE3(1612)).

M.C.S. acknowledges the financial support offered by the Sectorial Operational Program - Human Resources Development 2007-2013 of Romanian Ministry of Labor, Family and Social Protection through the Financial Agreement POSDRU/107/1.5/S/76903.

V.V.J. acknowledges the financial support offered by the Sectorial Operational Program Human Resources Development 20072013 of the Ministry of European Funds through the Financial Agreement POSDRU/159/1.5/S/132395.

\section{Appendix A. Supplementary data}

Supplementary data related to this article can be found at http:// dx.doi.org/10.1016/j.dyepig.2014.10.010.

\section{References}

[1] Papagiannouli I, Iliopoulos K, Gindre D, Sahraoui B, Krupka O, Smokal V, et al. Third-order nonlinear optical response of push-pull azobenzene polymers. Chem Phys Lett 2012;554(0):107-12.

[2] Lemouchi C, Iliopoulos K, Zorina I Simonov S, Wzietek P, Cauchy T, et al Crystalline arrays of pairs of molecular rotors: correlated motion, rotational barriers, and space-inversion symmetry breaking due to conformational mutations. J Am Chem Soc 2013;135(25):9366-76.

[3] Iliopoulos K, El-Ghayoury A, Derkowska B, Ranganathan A, Batail P, Gindre D, et al. Effect of the counter cation on the third order nonlinearity in anionic Au dithiolene complexes. Appl Phys Lett 2012;101(26):261105-14.

[4] Iliopoulos K, El-Ghayoury A, El Ouazzani H, Pranaitis M, Belhadj E, Ripaud E, et al. Nonlinear absorption reversing between an electroactive ligand and its metal complexes. Opt Express 2012;20(23):25311-6.

[5] Liu Z, Lu G-Y, Ma J. Tuning the absorption spectra and nonlinear optical properties of $D-\pi-A$ azobenzene derivatives by changing the dipole moment and conjugation length: a theoretical study. J Phys Org Chem 2011;24(7):568-77.

[6] Gindre D, Boeglin A, Fort A, Mager L, Dorkenoo KD. Rewritable optical data storage in azobenzene copolymers. Opt Express 2006:14(21):9896-901.

[7] Guo J, Gleeson MR, Sheridan JT. A review of the optimisation of photopolymer materials for holographic data storage. Phys Res Int 2012;2012:01-16.

[8] Gindre D, Iliopoulos K, Krupka O, Champigny E, Morille Y, Sallé M. Image storage in coumarin-based copolymer thin films by photoinduced dimerization. Opt Lett 2013;38(22):4636-9.

[9] Iliopoulos K, Krupka O, Gindre D, Sallé M. Reversible two-photon optical data storage in coumarin-based copolymers. J Am Chem Soc 2010;132(41):14343-5.

[10] Yesodha SK, Sadashiva Pillai CK, Tsutsumi N. Stable polymeric materials for nonlinear optics: a review based on azobenzene systems. Prog Polym Sci 2004;29(1):45-74. 
[11] El Ouazzani H, Iliopoulos K, Pranaitis M, Krupka O, Smokal V, Kolendo A, et al. Second-and third-order nonlinearities of novel push-pull azobenzene polymers. J Phys Chem B 2011;115(9):1944-9.

[12] Sekkat Z, Knoll W. Photoreactive organic thin films. San Diego: Academic Press; 2002.

[13] Gindre D, Ka I, Boeglin A, Fort A, Dorkenoo KD. Image storage through grayscale encoding of second harmonic signals in azo-dye copolymers. Appl Phys Lett 2007;90(9):094103-3.

[14] Czaplicki R, Krupka O, Essaidi Z, El-Ghayoury A, Kajzar F, Grote J, et al. Grating inscription in picosecond regime in thin films of functionalized DNA. Opt Express 2007;15(23):15268-73.

[15] Kawata S, Kawata Y. Three-dimensional optical data storage using photochromic materials. Chem Rev 2000;100(5):1777-88.

[16] Hagen R, Bieringer T. Photoaddressable polymers for optical data storage. Adv Mater 2001;13(23):1805-10.

[17] Bandara HMD, Burdette SC. Photoisomerization in different classes of azobenzene. Chem Soc Rev 2012;41(5):1809-25.

[18] Barrett CJ, Mamiya J-I, Yager KG, Ikeda T. Photo-mechanical effects in azobenzene-containing soft materials. Soft Matter 2007;3(10):1249-61.

[19] Zhao Y, Ikeda T. Smart light-responsive materials: azobenzene-containing polymers and liquid crystals. Hoboken: John Wiley \& Sons Inc; 2009.

[20] Zhu Y, Zhou Y, Wang X. Photoresponsive behavior of two well-defined azo polymers with different electron-withdrawing groups on push-pull azo chromophores. Dyes Pigm 2013;99(1):209-19.

[21] Fernández R, Etxeberria H, Eceiza A, Tercjak A. Enhanced stability of photoinduced anisotropy due to intermolecular interactions in an azo-prepolymer confined in block copolymer. Eur Polym J 2013;49(5):984-90.

[22] Goulet-Hanssens A, Barrett CJ. Photo-control of biological systems with azobenzene polymers. J Polym Sci Part A Polym Chem 2013;51(14):3058-70.

[23] Sava I, Hurduc N, Sacarescu L, Apostol I, Damian V. Study of the nanostructuration capacity of some azopolymers with rigid or flexible chains. High Perform Polym 2013;25(1):13-24.

[24] Sugita A, Sato Y, Ito K, Murakami K, Tamaki Y, Mase N, et al. Second-order nonlinear optical susceptibilities of nonelectrically poled DR1-PMMA guest-host polymers. J Phys Chem B 2013;117(47):14857-64.

[25] Kang X, Zhao J, Li H, He S. Synthesis of a main-chain liquid crystalline azopolymer via "click" chemistry. Colloid Polym Sci 2013:291(9):2245-51.

[26] Wang H, Jin F, Chen S, Dong X-Z, Zhang Y-L, Chen W-Q, et al. Preparation, photoisomerization, and microfabrication with two-photon polymerization of crosslinked azo-polymers. J Appl Polym Sci 2013;130(4):2947-56.

[27] Bosshard C, Hulliger J, Florsheimer M, Gunter P. Organic nonlinear optical materials. CRC Press; 2001.

[28] Marder SR. Organic nonlinear optical materials: where we have been and where we are going. Chem Commun 2006:2:131-4.

[29] Kajzar F, Lee K-S, Jen AY. Polymeric materials and their orientation techniques for second-order nonlinear optics. In: Lee K-S, editor. Polymers for photonics applications 2. Berlin: Springer Berlin Heidelberg; 2003. p. 1-85.

[30] Mortazavi MA, Knoesen A, Kowel ST, Higgins BG, Dienes A. Second-harmonic generation and absorption studies of polymer-dye films oriented by coronaonset poling at elevated temperatures. J Opt Soc Am B 1989;6(4):733-41.
[31] Spiridon MC, Jerca FA, Jerca VV, Vasilescu DS, Vuluga DM. 2-Oxazoline based photo-responsive azo-polymers. Synthesis, characterization and isomerization kinetics. Eur Polym J 2013;49(2):452-63.

[32] Singer KD, Sohn JE, Lalama SJ. Second harmonic generation in poled polymer films. Appl Phys Lett 1986;49(5):248.

[33] Bosshard C, Knöpfle G, Prêtre P, Günter P. Second-order polarizabilities of nitropyridine derivatives determined with electric-field-induced secondharmonic generation and a solvatochromic method: a comparative study J Appl Phys 1992;71(4):1594.

[34] McRae EG. Theory of solvent effects on molecular electronic spectra. frequency shifts. J Phys Chem 1957;61(5):562-72.

[35] Immirzi A, Perini B. Prediction of density in organic crystals. Acta Crystallogr Sect A Found Crystallogr 1977;33(1):216-8.

[36] Herman WN, Hayden LM. Maker fringes revisited: second-harmonic generation from birefringent or absorbing materials. J Opt Soc Am B 1995;12(3): 416-27.

[37] Spiridon MC, Jerca FA, Jerca VV, Vuluga DM, Vasilescu DS. Novel reactive monomers bearing a push-pull azo-moiety. Sci Bull Politeh Univ Buchar Ser B 2014;76(1):59-70.

[38] Teramachi S, Hasegara A, Atasuka M, Yamashita A, Takemoto N. Molecular weight distribution and correlation between chemical composition and molecular weight in a high-conversion copolymer of styrene-methyl acrylate. Macromolecules 1978;11:1206-10.

[39] Hagiopol C. Copolymerization: toward a systematic approach. New York: Kluwer Academic/Plenum; 1999.

[40] Nicolescu FA, Jerca VV, Vuluga DM, Vasilescu DS. Synthesis and characterization of side-chain poly(methacrylate)s bearing new azo-moieties. Polym Bull 2010;65(9):905-16.

[41] Brown D, Natansohn A, Rochon P. Azo polymers for reversible optical storage 5. Orientation and dipolar interactions of azobenzene side groups in copolymers and blends containing methyl methacrylate structural units. Macromolecules 1995;28(18):6116-23.

[42] Kwei TK. The effect of hydrogen bonding on the glass transition temperatures of polymer mixtures. J Polym Sci B Polym Lett Ed 1984;22(6):307-13.

[43] Schmidt MW, Baldridge KK, Boatz JA, Elbert ST, Gordon MS, Jensen JH, et al General atomic and molecular electronic structure system. J Comput Chem 1993:14(11):1347-63.

[44] Peverati R, Truhlar DG. Improving the accuracy of hybrid meta-GGA density functionals by range separation. J Phys Chem Lett 2011;2(21):2810-7.

[45] Dalton LR, Harper AW, Robinson BH. The role of London forces in defining noncentrosymmetric order of high dipole moment - high hyperpolarizability chromophores in electrically poled polymeric thin films. Proc Natl Acad Sci U S A 1997;94(10):4842-7.

[46] Iftime G, Fisher L, Natansohn A, Rochon P. Photoinduced birefringence in copolymers containing Disperse Red 1 and styrene. Can J Chem 2000;78(4): 409-14.

[47] Rau I, Armatys P, Chollet P-A, Kajzar F, Bretonnière Y, Andraud C. Aggregation: a new mechanism of relaxation of polar order in electro-optic polymers. Chem Phys Lett 2007;442(4):329-33. 